\title{
Eosinophilic Fasciitis with Prominent Immunologic Abnormalities
}

\author{
Kazuhide Yamane, MD, Haruhiko Ninomiya, MD, Mitsuru Shabana, MD, \\ Ichiro Kono, MD, Teizo Kabashima, MD, Tetsushi Sakurai, MD \\ and Heihachiro Kashiwagi, MD
}

\begin{abstract}
A 65-year-old male with eosinophilic fasciitis associated with positive rheumatoid factor and strongly positive Coombs tests (direct and indirect) is described. No Coombs positive case in this syndrome has been previously reported in the literature. Studies of the monocyte function suggested abnormalities of the monocyte-lymphocyte interaction which may partly explain the immunologic abnormalities found in this patients.
\end{abstract}

Key Words: Eosinophilic fasciitis, Coombs tests, Rheumatoid factor, Monocyte, Lymphocyte, Phytohemagglutinin

\section{INTRODUCTION}

Eosinophilic fasciitis is an uncommon syndrome characterized by induration of the skin of extremities and good response to corticosteroid $^{1,2)}$. Peripheral eosinophilia and hypergammaglobulinemia are frequently found, but reports of autoantibodies have been rare $^{3)}$. We describe a patient with eosinophilic fasciitis associated with prominent immunologic abnormalities. Studies of monocyte-lymphocyte interaction in this patient revealed an interesting result which may partly explain the immunologic abnormalities found in this patient.

\section{CASE REPORT}

A 65-year-old male tailor was admitted to the Tsukuba University Hospital with stiffness of forearms of 3 months' duration. The patient had been in excellent health until a trip to Europe in January 1981, when he noted difficulty in forward-bending of the spine, swelling of forearms, arthralgia of wrists and ankles, and myalgia of lower extremities with edema. There was a several months' history of erythema over the left upper quadrant of abdomen, which gradually extended to waist and bilateral lower legs. There was no history of Raynaud's phenomenon.

On admission, the patient appeared wellnourished and had normal vital signs. The skin over forearms was tight and indurated. The subcutaneous tissue of forearms appeared hide-bound. There were grooves along veins with puckering on the volar aspect of forearms. Flexion contractures of the right fourth and fifth proximal interphalangeal joints and bilateral elbow joints were noted. Both wrists demonstrated a decreased range of motion. There was no frank sclerodactyly or telangiectases. The skin of abdominal wall was tight enough to make palpation of liver difficult. There were scaly erythemas of various sizes at the left upper quadrant of abdomen, waist and bilateral lower legs. Laboratory evaluation revealed a hematocrit of $40.5 \%$, leukocyte count $8,000 / \mathrm{mm}^{3}$ ( $46 \%$ polymorphonuclear cells, $18 \%$ eosinophils, $34 \%$ lymphocytes, $2 \%$ monocytes), a reticulocyte count $33,000 / \mathrm{mm}^{3}$, a platelet count 356,000 / $\mathrm{mm}^{3}$ and Westergren erythrocyte sedimentation rate $10 \mathrm{~mm} / \mathrm{h}$. Total serum protein concentration was $7.0 \mathrm{~g} / \mathrm{dl}$ with $24.0 \%$ gammaglobulin on electrophoresis. Blood chemistry examinations revealed normal level of urea nitrogen, creatinine, uric acid, bilirubin, GOT, GPT, LDH, GPK, aldolase and haptoglobin. Routine urinalyses were negative.

From the Department of Internal Medicine, Institute of Clinical Medicine, The University of Tsukuba, Ibaraki Received for publication December 7, 1982.

Reprint request to: Kazuhide Yamane, MD, Department of Internal Medicine, Institute of Clinical Medicine, The University of Tsukuba, 2-1-1, Sakuramura, Niiharigun, Ibaraki, 305, Japan. 
Stools were negative for ova and parasites. The results of ANA test, anti-ENA antibody test and serologic test for syphilis were negative. Normal values were obtained for $\mathrm{CH} 50, \mathrm{C} 3$ and $\mathrm{C} 4$. Serum concentration of IgG was $1,621.9 \mathrm{mg} / \mathrm{dl}, \operatorname{IgA}$ $240.7 \mathrm{mg} / \mathrm{dl}$ and IgM $66.6 \mathrm{mg} / \mathrm{dl}$. Latex fixation test was positive $(1: 20)$ and CRP was positive (1+). LE cell was negative. Both direct and indirect Coombs tests were strongly positive. PPD skin test was ( \pm ).

Tests for pulmonary function and upper G-I series gave normal results. A full-thickness skin biopsy of left forearm that included underlying muscles revealed a markedly thickened fascia infiltrated with abundant plasma cells, lymphocytes and a few eosinophils (Fig. 1). The cellular infiltration was prominent perivascularly. Perivascular area in the deep dermis was also infiltrated with a dense accumulation of chronic inflammatory cells.

A diagnosis of eosinophilic fasciitis was made and the patient was started on $30 \mathrm{mg} /$ day of prednisolone. Within the first week of therapy, the patient noted improvement in stiffness of forearms and felt it much easier to bend his spine. Within 2 weeks grip strength increased from $5 \mathrm{~kg}$ to $15 \mathrm{~kg}$, and the distance between fingertip and floor decreased from $30 \mathrm{~cm}$ to $10 \mathrm{~cm}$. Edema and erythema disappeared more slowly. An absolute eosinophil count decreased from $1,440 / \mathrm{mm}^{3}$ to near 0 after 5 days' corticosteroid therapy. GRP and latex fixation test converted to negative. The Coombs tests (direct and indirect) changed from

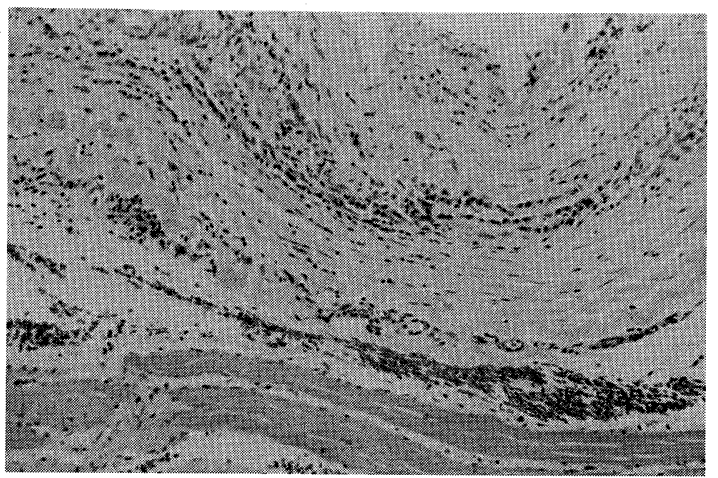

Fig. 1. Full-thickness biopsy of skin from left forearm demonstrating thickening and chronic inflammation of subcutaneous fascia. (Hematoxylin and eosin; original magnification $\times 75$.)
$(3+)$ to $(1+)$. Prednisolone was tapered during the next 6 months and there was a progressive increase in strength in the extremities.

\section{Study of Suppressive Effect of Monocytes on Lymphocyte Response to PHA}

The method for assaying suppressive effect of high concentrations of monocytes on lymphocyte response to phytohemagglutinin (PHA) has been described elsewhere ${ }^{4)}$. In brief, monocytes and lymphocytes were obtained from normal controls and the patient using density gradient centrifugation and cell adherence to plastic dish. The cell purity for lymphocytes and monocytes was more than $92 \%$ and $96 \%$, respectively. Lymphocytes $\left(1 \times 10^{5}\right)$ alone or lymphocytes mixed with the same number of autologous monocytes were cultured with $15 \mu \mathrm{g}$ PHA in PRMI 1640 medium containing $15 \%$ fetal calf serum for $96 \mathrm{hrs} .{ }^{3} \mathrm{H}$ thymidine $(0.25 \mu \mathrm{Ci})$ was added at $20 \mathrm{hrs}$ prior to completion of culture, followed by cell harvest and counting ${ }^{3} \mathrm{H}$-thymidine uptake by lymphocytes. The cell viability at 96 hours was greater than $85 \%$ as assessed by trypan blue exclusion.

In 6 normal controls, ${ }^{3} \mathrm{H}$-thymidine uptake $(16,470 \pm 2,780 \mathrm{cpm})$ by lymphocytes cocultured with the same number of monocytes decreased to a mean of $46.3 \%$ of the uptake $(35,573 \pm 4,532$ cpm) obtained when lymphocytes alone were cultured. In contrast, ${ }^{3} \mathrm{H}$-thymidine uptake $(47,297 \mathrm{cpm})$ by the patient's lymphocytes cocultured with monocytes increased to $137 \%$ of the uptake $(34,555 \mathrm{cpm})$ when lymphocytes alone were cultured.

\section{DISCUSSION}

The patient presented here meets the clinical and histologic criteria for eosinophilic fasciitis. Various reports of eosinophilic fasciitis emphasized that immunologic abnormalities were infrequent with the exception of hypergammaglobulinemia ${ }^{3,5,6)}$. Our patient, however, demonstrated hypergammaglobulinemia and rheumatoid factor, the latter having been reported in the literature ${ }^{7)}$. Further immunologic change in our patient was that there were strong positive results for both direct and indirect Coombs tests. Parallel with clinical improvement following corticosteroid therapy, Coombs test positivity decreased from 
$(3+)$ to $(1+)$. Coombs positive hemolytic anemia occurs rarely in progressive systemic sclerosis ${ }^{8,9)}$, a disease with certain similarities with eosinophilic fasciitis, however, to our knowledge no Coombs positive test has been reported in the latter syndrome. Recently Hoffman and his coworkers ${ }^{10}$ ) described a case of eosinophilic fasciitis associated with antibody mediated aplastic anemia. It is therefore conceivable that eosinophilic fasciitis may be more prone to association with autoimmune hematologic complication than heretofore considered. In our patient hemolytic anemia did not develop in spite of strongly positive Coombs tests. We would attribute this to early treatment with prednisolone.

The mechanism by which prominent serologic changes such as positive rheumatoid factor and Coombs antibody developed in our patient remains unknown. In this connection our observation on the impaired regulatory function of monocytes on lymphocyte response to PHA is interesting. In normal controls, autologous monocytes cocultured with the same number of lymphocytes suppressed proliferative response of lymphocytes to PHA. In contrast, monocytes from the patient failed to demonstrate this suppressive effect on autologous lymphocytes. Autoantibodies found in our patient could result from enhanced immunologic reactivities secondary to these aberrant lymphocyte-monocyte interactions. Furher studies on lymphocyte and monocyte functions in this syndrome may be rewarding.

\section{REFERENCES}

1) Shulman LE: Diffuse fasciitis with hypergammaglobulinemia and eosinophilia: a new syndrome? J Rheumatol 1(Suppl 1): 46, 1974.

2) Shulman LE: Diffuse fasciitis with eosinophilia: A new syndrome? Trans Assoc Am Physicians 88: $70,1975$.

3) Kent LT, Cramer SF, Moskowitz RW: Eosinophilic fasciitis - Clinical, laboratory, and microscopic considerations. Arthritis Rheum 24: 677, 1981.

4) Yamane K, Kono I, Kabashima T, et al: Suppressive effect of high concentrations of human monocytes on lymphocyte response to PHA. Jpn J Allergol 28: 689, 1979.

5) Bennett RM, Herron A, Keogh L: Eosinophilic fasciitis - Case report and review of the literature. Ann Rheum Dis 36: 354, 1977.

6) Moore TL, Zuckner J: Eosinophilic fasciitis. Semin Arthritis Rheum 9: 228, 1980.

7) Moutsopoulos HM, Webber BL, Pavlidis NA, et al: Diffuse fasciitis with eosinophilia. A clinicopathologic study. Am J Med 68: 701, 1980.

8) Ivey $\mathrm{KJ}$, Hwang Y-F, Sheets RF: Scleroderma associated with thrombocytopenia and Coombspositive hemolytic anemia. Am J Med 51: 815, 1971.

9) Michet, Jr. CJ, Doyle JA, Ginsburg WW: Eosinophilic fasciitis - report of 15 cases. Mayo Clin Proc 56: 27, 1981.

10) Hoffman R, Dainiak N, Sibrack L, et al: Antibodymediated aplastic anemia and diffuse fasciitis. $N$ Engl J Med 300: 718, 1979. 